\title{
CH4 IPDA LIDAR MISSION DATA SIMULATOR AND PROCESSOR FOR MERLIN: PROTOTYPE DEVELOPMENT AT LMD/CNRS/ECOLE POLYTECHNIQUE
}

\author{
Chomette Olivier $^{1 *}$, Raymond Armante ${ }^{1}$, Cyril Crevoisier $^{1}$, Thibault Delahaye ${ }^{1}$, Dimitri Edouart ${ }^{1}$, \\ Fabien Gibert ${ }^{1}$, Frédéric Nahan ${ }^{2}$, Yoann Tellier ${ }^{1}$
}

\author{
${ }^{1}$ Laboratoire de Météorologie Dynamique (LMD), Ecole Polytechnique, 91128 Palaiseau, FRANCE, \\ *chomette@lmd.polytechnique.fr \\ ${ }^{2}$ Magellium Paris, 92400 Courbevoie, FRANCE
}

\begin{abstract}
The MEthane Remote sensing Lidar missioN (MERLIN), currently in phase $\mathrm{C}$, is a joint cooperation between France and Germany on the development of a spatial Integrated Path Differential Absorption (IPDA) LIDAR (LIght Detecting And Ranging) to conduct global observations of atmospheric methane. This presentation will focus on the status of a LIDAR mission data simulator and processor developed at LMD (Laboratoire de Météorologie Dynamique), Ecole Polytechnique, France, for MERLIN to assess the performances in realistic observational situations.
\end{abstract}

\section{INTRODUCTION}

The major anthropogenic sources of $\mathrm{CH}_{4}$ are the emissions from energy production, landfills, waste treatment, cattle, rice fields and incomplete biomass burning. In addition there are significant natural $\mathrm{CH}_{4}$ sources from wetlands. Due to human activities, its concentration has been multiplied by more than 2 since the pre-industrial period (1750s) and currently reaches approximately 1800 ppb [1].

After carbon dioxide $\left(\mathrm{CO}_{2}\right)$, methane $\left(\mathrm{CH}_{4}\right)$ is the second anthropogenic greenhouse gas responsible for global warming. Although its global emissions (estimated at around $550 \mathrm{TgCH}_{4} \mathrm{yr}-1$ [2]) are only $4 \%$ of the global $\mathrm{CO}_{2}$ anthropogenic emissions in units of carbon mass flux, $\mathrm{CH}_{4}$ has a warming potential that is about 28 times higher than $\mathrm{CO}_{2}$. Today, surface methane emissions contribute approximately to $30 \%$ of the total radiative forcing either directly (20\%) [1] or indirectly (10\%) via contribution to tropospheric $\mathrm{O}_{3}$ and $\mathrm{H}_{2} \mathrm{O}$ production [1].
Understanding and monitoring the evolution of the mechanisms of sources and sinks of this gas in the atmosphere represents a major challenge to better anticipate the future climate. The goal of MERLIN is to obtain global measurements of the spatial and temporal gradients of atmospheric $\mathrm{CH}_{4}$ with a precision and accuracy sufficient to constrain methane fluxes significantly better than with the current observations made by passive optical radiometry techniques and limited in precision as well as in spatial and temporal coverage (cloud cover, aerosol interference, nighttime). The main driver for MERLIN are the specification on the $\mathrm{CH}_{4}$ column-weighted dry-air mixing ratio $\left(\mathrm{XCH}_{4}\right)$ split as precision (random error), maximum bias (systematic error) and horizontal sampling as given in Table 1.

Table 1 MERLIN mission requirement for $\mathrm{XCH} 4$

\begin{tabular}{|l|l|l|l|}
\hline & Threshold & Breakthrough & Target \\
\hline $\begin{array}{l}\mathrm{XCH}_{4} \\
\text { random error }\end{array}$ & $\begin{array}{l}36 \mathrm{ppb} \\
(2 \%)\end{array}$ & $\begin{array}{l}18 \mathrm{ppb} \\
(1 \%)\end{array}$ & $\begin{array}{l}8 \mathrm{ppb} \\
(0.5 \%)\end{array}$ \\
\hline $\begin{array}{l}\mathrm{XCH} \\
\text { systematic } \\
\text { error (bias) }\end{array}$ & $3 \mathrm{ppb}$ & $2 \mathrm{ppb}$ & $1 \mathrm{ppb}$ \\
\hline \multicolumn{2}{|l|}{ Resolution : 50 km horizontal ; total column vertical } \\
\hline
\end{tabular}

The very low level of systematic error aims at avoiding geographical biases in the $\mathrm{XCH}_{4}$ fields that could lead to uncertainties in fluxes.

In order to reduce the relative random error due mostly to the signal to noise ratio of the instrument, the data are going to be horizontally averaged over $50 \mathrm{~km}$ along track.

\section{THE MERLIN MISSION}

The payload is under the responsibility of the German space agency (DLR), while the platform (MYRIADE Evolutions product line) is developed by the French space agency (CNES). MERLIN is 
planned to be launch at the end of 2020. The IPDA technique relies on DIAL (Differential Absorption LIDAR) measurements using a pulsed laser emitting at two wavelengths, one wavelength accurately locked on a spectral feature of the methane absorption line, and the other wavelength free from absorption to be used as reference. More details about the instruments can be found in [3].

The MERLIN mission will provide the following data products:

Table 2 MERLIN products

\begin{tabular}{|c|l|}
\hline $\begin{array}{c}\text { Level } \\
0\end{array}$ & $\begin{array}{l}\text { For each individual laser shot the range- } \\
\text { gated backscatter signal data together with } \\
\text { auxiliary data such as laser pulse energy, } \\
\text { ranging information, wavelength in a } \\
\text { chronological data sequence. }\end{array}$ \\
\hline $\begin{array}{c}\text { Level } \\
\text { 1a }\end{array}$ & $\begin{array}{l}\text { Level 0 data with all calibrations computed } \\
\text { and appended. }\end{array}$ \\
\hline $\begin{array}{c}\text { Level } \\
\text { 1b }\end{array}$ & $\begin{array}{l}\text { Integrated signal at echo for off and on } \\
\text { wavelengths, range, SNR, slant-path } \\
\text { DAOD, geo-location and time. }\end{array}$ \\
\hline $\begin{array}{c}\text { Level } \\
2\end{array}$ & $\begin{array}{l}\text { Column-weighted dry-air mixing ratios of } \\
\text { methane (XCH } \\
\text { averaged. }\end{array}$ \\
\hline $\begin{array}{c}\text { Level shot-by-shot and } \\
3\end{array}$ & $\begin{array}{l}\text { Visualizations of level 2 data such as } \mathrm{XCH}_{4} \\
\text { maps. }\end{array}$ \\
\hline
\end{tabular}

Level 1 is the responsibility of DLR, Level 2 and 3 are the responsibility of CNES.

We present here the MERLIN measurement principles and the work developed within the MERLIN team at LMD in regards to the LIDAR signals simulation with LIDSIM (LIDar SIMulator) to be able to simulate the Level 0/1a data (see Table 2) and the inversion of this signal done with PROLID (PROcessor LIDar) to obtain the Level $1 \mathrm{~b}$ and Level 2 product (see Table 2), the column-weighted dry-air mixing ratios of $\mathrm{CH}_{4}$, referred to as $\mathrm{XCH}_{4}$, over the satellite sub-track.

\section{MEASUREMENT PRINCIPLE}

The core element of the MERLIN mission is the nadir-viewing CH4 IPDA LIDAR system. This instrument measures the light back-scattered from the Earth's surface and cloud tops which are illuminated by laser pulses having slightly different wavelengths denoted as $\lambda_{\text {on }}$ and $\lambda_{\text {off }}$ (Fig. $1)$.

The online wavelength $\lambda_{\text {on }}$ is accurately positioned in the trough of one of the $\mathrm{CH} 4$ absorption line multiplets in the $1.64 \mu \mathrm{m}$ near-infrared spectral region in order to dramatically relax the laser frequency stability and platform pointing requirements.

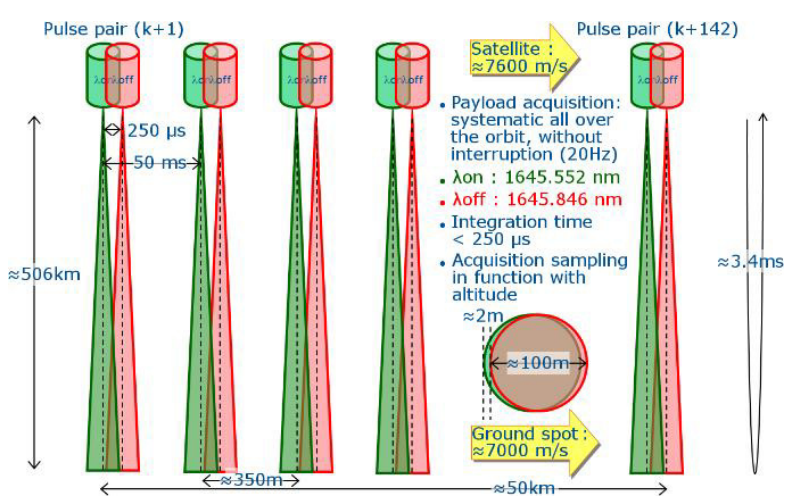

Figure 1 MERLIN measurements concept

The measurement at $\lambda_{\text {off }}$ serves as the reference measurement with negligible absorption by the $\mathrm{CH}_{4}$ molecules in the path. The on and off wavelengths are spectrally close enough to consider the atmospheric and surface properties to be identical with the exception of $\mathrm{CH}_{4}$ absorption (and $\mathrm{H}_{2} \mathrm{O}$ and $\mathrm{CO}_{2}$ absorption in a second order). The MERLIN measurement concept is described in Fig. 1.

\section{LIDSIM \& PROLID}

\subsection{LIDSIM}

The objective of LIDSIM and PROLID is to be used to assess the performance of MERLIN in realistic observational situations (i.e. terrain characteristics, atmospheric conditions).

The inputs of LIDSIM are composed of three modules (Fig. 2)

- The geometry module provides a simulated MERLIN orbit with latitude/longitude of each shot with respect to LIDAR line of sight pointing, satellite altitude, solar zenith angle and time of the shots.

- The scene generation module provides information on the atmospheric conditions and the surface characteristics from different data sources:

o Atmospheric profiles ( $\mathrm{T}, \mathrm{P}, \mathrm{H}_{2} \mathrm{O}, \mathrm{O}_{3}$ ), $\mathrm{P}$ and $\mathrm{T}$ at surface from ECMWF.

o Some information from a Data Elevation Model (DEM) to derive the altitude of each 
shot but also the terrain's slope and its roughness. We currently use GMTED2010.

o A global land cover product (GlobCover) to have information about land cover for each shot. This information helps us to create different surface echo linked to land cover classes (all our surface echoes are Gaussian, only the width is modified).

o A database produced from MODIS data to derive the surface reflectivity.

o An inundation climatology to take into account the modifications of surface characteristics brought by inundations.

- The instrument module provides all the instrument characteristics needed to simulate the LIDAR signal in LIDSIM (laser emission, telescope receiver, optics unit, detection and digitalization units).

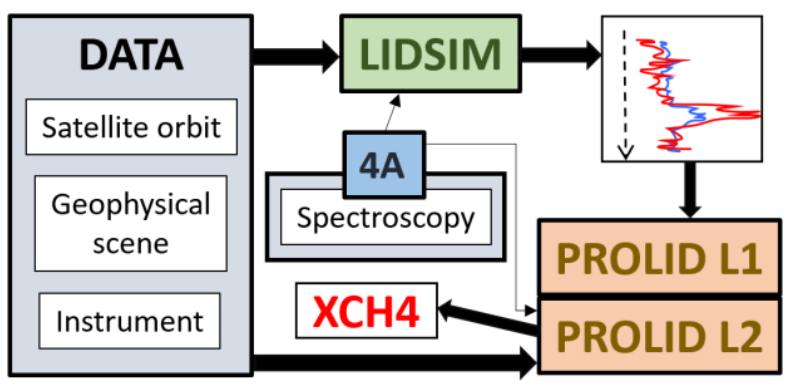

Figure 2 Schematic description and flow diagram of the LIDSIM/PROLID chains

The core of LIDSIM determines the photoelectrons number from the signal (i.e. the photoelectrons detected after being reflected by the ground or a cloud taking into account the absorption and extinction due to the atmosphere) but also from the background (i.e. the photoelectrons generated by the sky background). This step needs a great accuracy on spectroscopic information for the $\mathrm{CH}_{4}$ multiplet but also for the $\mathrm{H}_{2} \mathrm{O}$ and $\mathrm{CO}_{2}$ in the vicinity of the two MERLIN wavelengths, two gases whose effects must be taken into account in the radiative transfer calculations. For the spectroscopy, GEISA database is used [4] and the Automatized Atmospheric Absorption Atlas (4A) [5] a fast and accurate line-by-line radiative transfer model particularly efficient in the infrared region of the spectrum is used for the radiative computation.

Noise is then added on the signal (laser and background shot noise, laser and background speckle, noise from the detector and from the detection chain). The detection impulse response is also taken into account. The Fig. 3 shows an example of a signal output from LIDSIM.

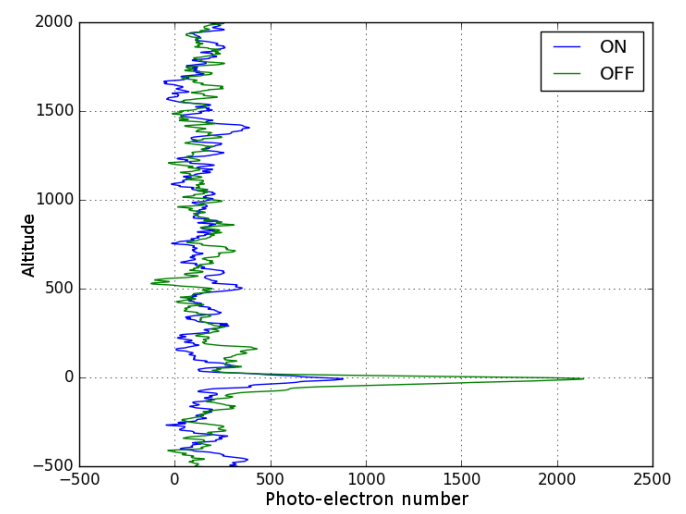

Figure 3 LIDSIM output example. Lidar signal (with noise) for the MERLIN ON and OFF wavelengths

\subsection{PROLID}

The LIDSIM outputs are directly processed by PROLID. This processor works in two steps. The first one, PROLID-L1, creates MERLIN-L1b like data. Then we obtain the MERLIN-L2 like data $\left(\mathrm{XCH}_{4}\right)$ with PROLID-L2. The LIDSIM inputs (Fig. 2) are also needed for PROLID.

PROLID-L1 is still under development at LMD. It is based on the algorithm proposed by DLR. As the impulse response of the detection chain is asymmetrical, the ground echo signal is altered (cf. the asymmetry of the ground echo in Fig. 3). Using a deconvolution process, the asymmetry of the impulse response is rectified and then, the range bias estimation is reduced. PROLID-L1 will also retrieve the scattered energy from the ground echoes and the related SNR for each simulated laser shots.

From the ratio of the LIDAR echoes $\mathrm{P}_{\text {on }} / \mathrm{P}_{\text {off }}$, the Differential Absorption Optical Depth (DAOD) and thus the main data product $\mathrm{XCH}_{4}$ (defined as a vertical column averaged by a weighting function WF) can be calculated using the following set of equations

$$
X C H 4=\frac{\int_{0}^{P s u r f}[C H 4] W F(p) d p}{\int_{0}^{P s u r f} W F(p) d p}=\frac{D A O D}{\int_{0}^{P s u r f} W F(p) d p}
$$




$$
\begin{gathered}
\text { where } D A O D=\frac{1}{2} \ln \left(\frac{P_{o n}}{P_{o f f}}\right) \\
\text { and } W F=\frac{\sigma\left(\lambda_{o n}, P, T\right)-\sigma\left(\lambda_{o f f}, P, T\right)}{g\left(m_{d r y}+m_{H 2 O} \chi_{H 2 O}\right)}
\end{gathered}
$$

With $\mathrm{P}, \mathrm{T}$ the vertical profile of pressure and temperature, $\sigma$ the methane absorption crosssection (in $\mathrm{m}^{2}$ ), $\mathrm{m}$ is the molecular mass of a species and ${ }_{\mathrm{H} 2 \mathrm{O}}$ is the vertical profile of the volume mixing ratio of water vapor with respect to dry air.

To calculate the WF (eq. 3) we need to know the effective absorption cross sections of at least the three atmospheric species $\mathrm{CH}_{4}, \mathrm{CO}_{2}$ and $\mathrm{H}_{2} \mathrm{O}$. These cross sections depend on atmospheric temperature, pressure and composition and are calculated using 4A. The SSE (Scattering Surface Elevation) needs to be determined in PROLID-L1 in order to know more precisely the surface pressure as the WF is integrated between the top of the atmosphere and the surface.

Once $\mathrm{XCH}_{4}$ (Eq. 1) is obtained shot by shot, a last module in PROLID-L2 performs the averaging over $50 \mathrm{~km}$. The method used is described in [6].

Currently the LIDSIM/PROLID-L2 chain is functional and validated. To validate it, we choose to work with TIGR (Thermodynamic Initial Guess Retrieval) dataset instead of an orbit as input. TIGR is a climatological library of 2311 representative atmospheric situations selected by statistical methods from 80,000 radiosonde reports [7]. Each situation is described, from the surface to the top of the atmosphere, by the values of $\mathrm{T}$, $\mathrm{H}_{2} \mathrm{O}, \mathrm{O}_{3}$ on a given pressure grid.

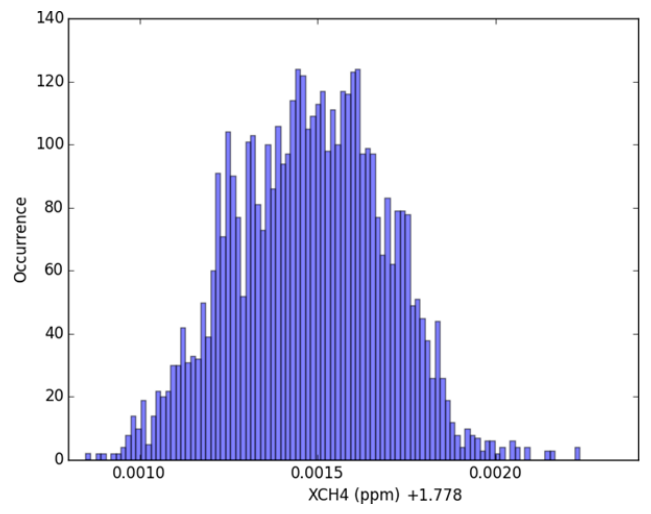

Figure 4 PROLID-L2 output XCH4 example without noise and over the TIGR database
With this database, all atmospheric conditions are taken into account while optimizing time calculation compared to use the orbit data. We also studied the impact of surface reflectivity by adding random value on TIGR. We validate our chain by comparing the $\mathrm{XCH}_{4}$ calculated by PROLID with the one put as input in LIDSIM without adding noise on the signal. We've found $1.7795 \pm 0.0002$ ppm (Fig. 4) out of PROLID over the all TIGR database with an amount of $\mathrm{CH}_{4}$ of $1.78 \mathrm{ppm}$ as input of LIDSIM.

\section{PERSPECTIVES}

In the future, in addition to complete PROLID-L1, several improvements are planned to be developed in our LIDSIM/PROLID chain such as a better vertical discretization, a more representative surface echo, taking into account the Doppler effect, the aerosols and the clouds.

\section{References}

[1] IPCC, 2013: Climate Change 2013: The Physical Science Basis. Contribution of WG I to the Fifth Assessment Report of the Intergovernmental Panel on Climate Change. Cambridge University Press, Cambridge, United Kingdom and New York, NY, USA, $1535 \mathrm{pp}$.

[2] Kirschke, S. et al..: Three decades of global methane sources and sinks, Nat. Geosci., 6, 813-823, doi:10.1038/ngeo1955, 2013.

[3] Stephan, C. et al.: 2011: MERLIN: a Spacebased Methane Monitor, Proceedings of the SPIE, Volume 8159, 815908-15.

[4] Jacquinet-Husson, N.et al.:The 2009 edition of the GEISA spectroscopic database. Journal of Quantitative Spectroscopy \& Radiative transfer, 2011, 112, pp.2395-2445.

[5] Cheruy,F. et al.: Contribution to the development of radiative transfer models for high spectral resolution observations in the infrared. Journal of Quantitative Spectroscopy and Radiative Transfer, Volume 53, Issue 6, June 1995, Pages 597-611.

[6] Tellier.Y. et al.: Averaging Bias Correction for Future IPDA Lidar Mission MERLIN, ILRC28 Proceeding (submitted)

[7] Chevallier,F. et al.: TIGR-like atmosphericprofile databases for accurate radiative-flux 
computation. Quart. J. Roy. Meteorol. Soc. 2000, 126, 777-785. 